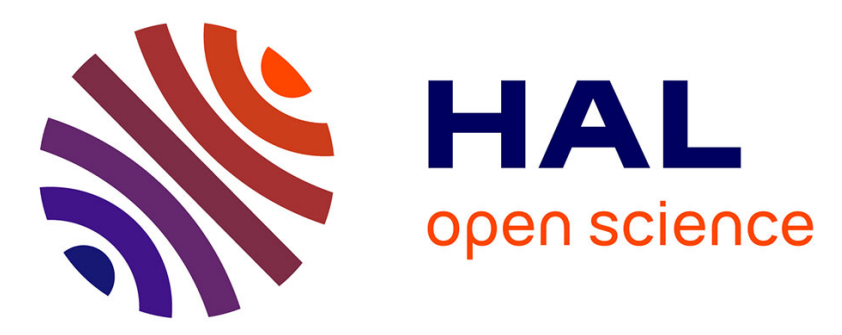

\title{
Assembly of chemically modified G-rich sequences into tetramolecular DNA G-quadruplexes and higher order structures
}

\author{
Jun Zhou, Dursun Nizam Korkut, Frédéric Rosu, Samir Amrane, Valérie \\ Gabelica, Jean-Louis Mergny
}

\section{To cite this version:}

Jun Zhou, Dursun Nizam Korkut, Frédéric Rosu, Samir Amrane, Valérie Gabelica, et al.. Assembly of chemically modified G-rich sequences into tetramolecular DNA G-quadruplexes and higher order structures. Methods, 2014, Nucleic Acids Nanotechnology, 67, pp.159 - 168. 10.1016/j.ymeth.2014.01.004 . inserm-01385785

\section{HAL Id: inserm-01385785 https://www.hal.inserm.fr/inserm-01385785}

Submitted on 22 Oct 2016

HAL is a multi-disciplinary open access archive for the deposit and dissemination of scientific research documents, whether they are published or not. The documents may come from teaching and research institutions in France or abroad, or from public or private research centers.
L'archive ouverte pluridisciplinaire HAL, est destinée au dépôt et à la diffusion de documents scientifiques de niveau recherche, publiés ou non, émanant des établissements d'enseignement et de recherche français ou étrangers, des laboratoires publics ou privés. 


\title{
Assembly of chemically modified G-rich sequences into tetramolecular DNA G-quadruplexes and higher order structures
}

Jun Zhou ${ }^{1,2}$, Dursun Nizam Korkut ${ }^{1,2}$, Frédéric Rosu ${ }^{3}$, Samir Amrane ${ }^{1,2}$, Valérie Gabelica $^{1,2^{*}}$ and Jean Louis Mergny ${ }^{1,2^{*}}$

${ }^{1}$ Univ. Bordeaux, ARNA laboratory, F-33000 Bordeaux, France.

${ }^{2}$ INSERM U869, IECB, F-33600 Pessac, France.

${ }^{3}$ INSERM US001, CNRS UMS 3033, IECB, F-33600 Pessac, France.

Correspondence may be addressed to J.L.M. (jean-louis.mergny@inserm.fr) or V.G. (v.gabelica@iecb.u-bordeaux.fr).

\begin{abstract}
In this review, we introduce the biophysical and biochemical methods currently used to investigate the structures and stabilities of tetramolecular DNA G-quadruplexes containing chemical modifications. We hope this paper will guide others as they perform similar experiments leading to more information about the effects of chemical modifications on G-quadruplex formation. The structures of tetramolecular quadruplexes and some higher order structures based on tetramolecular quadruplexes are also described.
\end{abstract}

Keywords:G-quadruplex, chemical modification, UV, CD, NMR 


\section{Introduction}

G-rich sequences can self-assemble to form non-canonical four-stranded structures called G-quadruplexes (G4) in the presence of certain cations [1-4]. Bioinformatic results demonstrated that sequences with the potential to form are found throughout the human genome [5,6], and a recent work visualized G4 in human cells [7]. These observations and a number of other results suggest that G4s play important roles in biological processes. In addition, G4s have garnered considerable attention beyond biology: They may find applications in the nanotechnology and the supramolecular chemistry fields [8-11]. G4 structures of one, two, and four strands have been well characterized [12], and we recently demonstrated that G4 can also be assembled from three strands [13]. Higher order structures involving more than four strands may also be formed. Among these, tetramolecular G4s are of special interest because of their symmetry and simplicity. First, tetramolecular G4s are parallel structures formed by short strands of nucleic acid each bearing a single guanine tract, guanine residues are nearly always in the anti glycosidic conformation, and all grooves are of medium size (Fig. 1). Second, this structure is kinetically inert, except at very high strand concentration [14-16], which facilitates experimental studies. Furthermore, once tetramolecular G4 forms, these structures are thermally stable, especially in solution containing potassium.

Tetramolecular G4 can be formed by natural DNA and RNA and also by chemically modified oligonucleotides. Altering the chemical composition of the G-rich strand is of interest for biotechnological applications (to stabilize aptamer sequences, for example) and to help us understand the exact role of each component. In this review, we focus on the methods of investigating chemically modified tetramolecular G4 structure and stability. It should be noted that tetramolecular G4 may incorporate natural bases and form unusual quartets with canonical nucleobases (A-, T-, C-, or U-quartets), which are described in our previous reviews $[17,18]$. In addition, we briefly discuss the self-assembly of tetramolecular G4 and higher order structures.

\section{Sample preparation}

Starting with pure samples is necessary. HPLC purification followed by mass spectrometry, denaturing gel and/or NMR analysis is recommended. When studying the association step, one should make sure the oligonucleotides are in a single-stranded form when solubilized in pure bidistilled water. Traces of counterions present during synthesis may allow the formation of complexes that can be observed by ESI-MS. To ensure that all oligonucleotides are single-stranded, one can pre-treat the sample with lithium hydroxide ( $\mathrm{LiOH}, 50-100 \mathrm{mM}$ for 15-30 min) to denature the complexes and then neutralize with an equal amount of $\mathrm{HCl}(\mathrm{pH}$ should be checked after this step). Thus, oligonucleotide stock solutions will be made in 50-100 mM 
$\mathrm{LiCl}$, rather than in pure water, and the amount of lithium salt added should be taken into consideration when final buffer conditions are determined. $\mathrm{Li}^{+}$may be considered as neutral towards G4, as it neither promotes nor denatures G-quadruplexes.

To guarantee that all the oligonucleotides assemble into G4 in solution, chemically modified sequences should be prepared at high strand concentration to favour intermolecular assemblies, and stored for several days or longer prior to analysis to ensure that equilibrium is reached. First heating the sample at relatively high temperature $\left(90^{\circ} \mathrm{C}\right.$, unless the chemical modification affects the chemical stability of the sample) for a few minutes, followed by slow cooling (1h to overnight) to room temperature or lower is a standard procedure for preparation of the samples. Kinetics of tetramolecular quadruplex formation is faster at lower temperatures than at higher temperatures; therefore, a low incubation temperature such as $4{ }^{\circ} \mathrm{C}$ is recommended. Oligonucleotide concentration should be higher than $100 \mu \mathrm{M}$, and the concentration of cations $\left(\mathrm{Na}^{+}\right.$or $\left.\mathrm{K}^{+}\right)$should be sufficient to allow efficient G4 formation $(0.1 \mathrm{M}$ or more is recommended; note that some G4 may form at much lower $\mathrm{K}^{+}$concentrations, in the $\mu \mathrm{M}$ range). For subsequent biophysical characterization, one can dilute the concentrated samples in an appropriate buffer. We generally use a lithium cacodylate bufferat $\mathrm{pH} 7.2$, supplemented with $0.1 \mathrm{M} \mathrm{KCl}$ or $\mathrm{NaCl}$. One of the very important issues that should be mentioned here is that a suitable cation must be chosen. TGGGT does not form stable G4 in sodium and should therefore be prepared in potassium, whereas TGGGGT already forms very stable G4 in the presence of sodium. Therefore, when preparing chemical modified samples, we recommend:

- starting in $\mathrm{K}^{+}$for $\mathrm{TG}_{3} \mathrm{~T}$ derivatives,

- $\quad$ using $\mathrm{Na}^{+}$or $\mathrm{NH}_{4}{ }^{+}$for $\mathrm{TG}_{4} \mathrm{~T}$ when comparing thermal stability $\left(\mathrm{TG}_{4} \mathrm{~T}\right.$ will not melt in $\mathrm{K}^{+}$) and $\mathrm{K}^{+}$for all other applications.

Note that mass spectrometry requires evaporable salts, so $\mathrm{NH}_{4}{ }^{+}$is desirable for most MS experiments (see $\S 3.4$ ).

\section{Evidence for G-quadruplex formation}

Confirmation of G4 formation is essential. A number of methods can be used to provide evidence of quadruplex formation and to determine whether single or multiple species are present.

\subsection{Circular dichroism (CD)}

$\mathrm{CD}$ is a convenient and sensitive tool that has been widely used to investigate the conformations of nucleic acids. CD requires limited amounts of sample. As described in many reports, short oligonucleotides containing a single block of guanines generally exhibit type I CD spectra (referred as "parallel" previously) characterized by a positive peak at $260 \mathrm{~nm}$ and a negative band at $240 \mathrm{~nm}$. A number of reviews 
have covered this topic [19-22]. The main issue that should be emphasized is that not all the chemically modified sequences exhibit a type I signal. As shown in Fig. 2A, the spectrum of the natural sequence $\mathrm{TG}_{4} \mathrm{~T}$ (TGGGGT) shows typical features of type I G4, and the spectrum of the oligonucleotide TGGGGT(TNA1) (underlined bases mean modified guanine analogs) modified with an acyclic threoninol nucleic acid is similar to the natural counterpart. However, the modified sequence TNA3 (TGGGGT) has a considerable different CD spectrum with two maxima peaks at near $290 \mathrm{~nm}$ and $252 \mathrm{~nm}$ and two minima around $271 \mathrm{~nm}$ and $232 \mathrm{~nm}$ [23]. CD spectrum is also sensitive to temperature, as shown for TNA3 in Fig. 2B; in this case, the spectrum is indicative of a mixture of G4 species in solution, which was demonstrated by molecular modeling results [23]. Chemical modifications may result in the formation of unusual G-tetrad stacking arrangements that affect CD. In fact, many chemically modified tetramolecular G4s exhibit atypical CD profiles. For example, G4 structures formed by 5'TGG3'-3'GGT5', which contains a $3^{\prime}-3^{\prime}$ inversion of polarity site in the G-tract sequence and by TGGGGT, in which the two underlined guanine bases were substituted by 8-methyl-2'-deoxyguanosine residues, both show CD spectra similar to TNA3 [24,25]. Two recent reviews explain these atypical CD spectra in detail $[22,26]$. Therefore, CD can be used as an initial approach to reveal the structural arrangements of chemically modified sequences, but it should be used with caution to attribute strand orientation. Overall, CD should be considered as complementary to other methods such as NMR and MS in a quadruplex investigation.

One can also use CD (or UV absorbance) to follow the thermal dissociation of preformed G4 to determine thermodynamic parameters and explore kinetics of tetramolecular G4 formed by chemical modified sequences. This type of study will be described in Chapter 4.

\subsection{UV absorbance, thermal difference spectra (TDS), and isothermal difference} spectra (IDS)

G-quadruplex formation can also be detected by UV absorption spectra. For instance, the spectra of sequences that have formed G4 show both a hypochromic and a hyperchromic sigmoid transition at 295 and $240 \mathrm{~nm}$, respectively [27]. We may consider two types of difference spectra called TDS and IDS.

- $\quad$ The TDS is obtained by subtracting the UV absorbance spectra of the folded (below the melting temperature, $T_{\mathrm{m}}$, and typically at room temperature) from the unfolded (above $T_{\mathrm{m}}$, at high temperature) states of the sample. Quadruplexes exhibit a negative peak around $295 \mathrm{~nm}$, and two positive peaks around 275 and $243 \mathrm{~nm}$, respectively [28].

- $\quad$ The features of the IDS are similar to those of TDS, and IDS are obtained by calculating the difference between the absorbance spectra of the folded and unfolded forms of a sample. Therefore, for very stable samples which do not dissociate at high temperature, one may perform IDS rather than TDS. 
As shown in Fig. 3A, the IDS profiles of chemically modified sample TNA1, TNA3, and their natural counterparts $\mathrm{TG}_{4} \mathrm{~T}$ were relatively similar (with two positive peaks at 240 and $273 \mathrm{~nm}$, and negative peak at $295 \mathrm{~nm}$ ), providing evidence that these chemically modified samples form G4 structures [23]. In addition, TDS of these samples (except for that of $\mathrm{TG}_{4} \mathrm{~T}$, which is very stable), resemble the IDS spectra (Fig.3B) [23]. To proceed, one may compare the absorbance spectra of the oligonucleotide in the absence of stabilizing salts and after potassium or sodium addition. To make sure a significant proportion of the strands adopt G4, samples should be incubated at least overnight at a relatively high strand concentration. This sample may then be diluted immediately prior to absorbance measurement, or transferred to a cuvette with a short pathlength. Maximum absorbance depends on the instrument - linearity should be determined prior to the experiment.

It should be noted that TDS and IDS can be used to determine G4 formation but not necessarily the type of quadruplex structure. A recent work suggested that using the ratio $\Delta \mathrm{A}_{240 \mathrm{~nm}} / \Delta \mathrm{A}_{295 \mathrm{~nm}}$ (absolute values of TDS), one could distinguish different types of G4 [29]. However, it remains to be determined whether this ratio can be applied to chemically modified sequences, especially when guanine analogues are considered. Overall, UV absorbance, like CD methods described above, is useful but should be used in conjunction with other methods.

\subsection{PAGE}

A simple method to demonstrate tetramolecular G4 formation is non-denaturing polyacrylamide gel electrophoresis (PAGE). The principle is that the formation of G4 by chemical modified sequences will result in the appearance of a band of retarded mobility as compared the same sequence in single-stranded form (prepared in the absence of G4-promoting salts). For example, we have replaced natural guanines in TGGGGT by 8-methylguanine one at a time. On native PAGE all of the chemically modified sequences exhibited a retarded migration in the presence of potassium ions (indicated by “+”) as compared to matching single-stranded controls (indicated by “-”) (Fig. 4A) [30]. To perform PAGE experiments, one should follow these guidelines:

i) Sample preparation. To achieve complete G4 formation, high concentrations of samples should be prepared as described in Chapter 2. In parallel, single-stranded samples should be prepared by incubation of the oligonucleotides in $50 \mathrm{mM} \mathrm{LiOH}$ at $37{ }^{\circ} \mathrm{C}$ for $15 \mathrm{~min}$ and then be neutralized with $50 \mathrm{mM} \mathrm{HCl}$. Alternatively, samples can be heated at $95{ }^{\circ} \mathrm{C}$ in pure water for $5 \mathrm{~min}$ and then put quickly onto ice. Prior to loading, 10\% sucrose may be added.

ii) Gel preparation. Samples are loaded on a $20 \%$ polyacrylamide non-denaturing gel. The gel is prepared with an acrylamide/bis-acrylamide ratio of 19:1; typical dimensions are is $13 \mathrm{~cm} \times 12 \mathrm{~cm} \times 0.2 \mathrm{~cm}$. The gel should contain $1 \mathrm{X}$ TBE supplemented with $10 \mathrm{mM} \mathrm{KCl}$ or $\mathrm{NaCl}$ (according the cations used for samples); the composition of the running buffer should be the same. One should be aware that the difference in mobility between single-strand and G4 depends on gel conditions. Note 
that changing acrylamide content may alter the results. For example, in $12 \%$ acrylamide, the G4 may migrate faster than the single-strands (results not shown)! In fact, for modified sample TNA1, in $20 \%$ acrylamide, we did not observe any mobility difference between G4 and single-stranded controls (Fig. 4B). These data confirm that non-denaturing PAGE migration is not directly related to size but is impacted by shape and global charge, taking into account counterion condensation.

iii) Electrophoresis. Gels should be electrophoresed at $3 \mathrm{~W} / \mathrm{gel}$ or less, to keep temperature close to $20^{\circ} \mathrm{C}$ (temperature can also be controlled by a water bath). The gel should be pre-run for about 30 min before loading samples.

iv) Data analysis. Different techniques are available to reveal nucleic acid bands on a gel. We tend to favor UV shadowing (using a UV source around $254 \mathrm{~nm}$ close to absorbance maximum of nucleic acids), as band intensity does not depend on the nature of the structure. Radioactivity is far more sensitive, but we tend to avoid radioactive labeling as addition of a 5 ' terminal phosphate modifies the charge of the oligonucleotide and affects migration and stability. Finally, a number of nucleic acid dyes may be used to stain a gel; keep in mind that staining intensity depends on the chemical nature and structure and, as a consequence, band intensity does not always reflect the relative abundances of the species.

In summary, although native PAGE is simple and intuitive, it should be used with caution, optimized, and confirmed with other techniques.

\subsection{Mass spectrometry}

With chemically modified oligonucleotides, mass spectrometry is important firstly for the quality control of the single strands, to ensure that the correct modification has been incorporated and that all deprotection steps went to completion, and to characterize the presence of minor contaminants (typically strands with one missing base). For mass measurements on synthetic single strands, we typically dilute the oligonucleotide strand to $10 \mu \mathrm{M}$ in pure water, then supplement the solution with 10 $\mathrm{mM}$ ammonium acetate $\left(\mathrm{NH}_{4} \mathrm{OAc}\right)$ after dilution. This procedure minimizes the sodium adduct detection, and these diluted conditions prevent tetramolecular G-quadruplex formation on the hour time scale. We add 50\% methanol just before the analysis and analyze the sample by electrospray mass spectrometry (ESI-MS). A recent review on mass spectrometry of structurally modified DNA provides a broad perspective on the analysis of these types of samples [31].

For multi-stranded structures, mass spectrometry is a straightforward way to determine the stoichiometry of strand assembly. A review on mass spectrometry of G-quadruplexes, comprehensively covering the literature up to 2009 is available [32]. We will focus here on mass measurements of sequences forming tetramolecular assemblies, and on some aspects relevant to modified sequences. The first mass spectra of a tetramolecular G-quadruplex assembly was published 20 years ago [33]. Those spectra, acquired in $10 \mathrm{mM}$ sodium phosphate buffer, displayed broad peaks 
due to the heterogeneity in number of sodium adducts. In 2002, high-resolution ESI-MS spectra of the tetramolecular G-quadruplex formed by TGGGGT were obtained in ammonium acetate rather than sodium phosphate [34]. Ammonium acetate has multiple roles: It ensures sufficient ionic strength for the multi-stranded assemblies to form, replaces non-volatile alkali ions with volatile ammonium ions around the negatively charged phosphates, and buffers the medium and enables G-quadruplex formation by specific coordination of ammonium cations between the G-quartets. To prepare tetramolecular G-quadruplexes in ammonium, the procedure is the same as described in Chapter 2. Note, however, that tetramolecular G-quadruplexes are generally slower to form in ammonium than in sodium or in potassium [17].

It is also possible to prepare multi-stranded structures in other cations, and then replace the non-coordinated cations by ammonium cations using ethanol precipitation [35] or filtering [36] procedures. The nature of the cations remaining trapped in the assemblies detected by ESI-MS will therefore depend on the speed of cation exchange in solution. For $\mathrm{K}^{+}$and tetramolecular structures, exchange for ammonium is slow and inner potassium ions can be detected [35].

Typically, the solutions injected onto the mass spectrometer contain $\sim 20 \mu \mathrm{M}$ single strand ( $\sim 5 \mu \mathrm{M}$ tetramolecular G-quadruplex) and from 50 to $200 \mathrm{mM} \mathrm{NH}_{4} \mathrm{OAc}$. Methanol can be added to the solution to obtain a stable spray and higher ion signals, but it is important to note that organic co-solvents influence G-quadruplex formation kinetics and final structures in solution [37,38]. Therefore, if ESI-MS data are to be compared with other spectroscopic data acquired in aqueous solution, it is important to acquire the ESI-MS data in aqueous solution in order that meaningful comparisons can be made.

Pierce et al. applied ESI-MS to study the self-assembly of dTGGGGTTTT and the equivalent with modified base isoguanine (Ig): dTIgIgIgIgTTTT. The results in the presence of several different cations are shown in Fig. 5. The natural sequence forms a tetramolecular assembly (Fig. 5A, denoted Q) except in $\mathrm{Cs}^{+}$where only single-strand is detected. The quadruplex takes up three ammonium cations when prepared in ammonium acetate directly, and this number corresponds to the three coordination sites between the four G-quartets. Quadruplexes prepared in $\mathrm{K}^{+}$or $\mathrm{Ba}^{2+}$ retain predominantly three inner potassium ions or two barium ions, respectively. In contrast, quadruplexes prepared in $\mathrm{Rb}^{+}$had their inner cations almost completely replaced by ammonium upon cation exchange. Fig. 5B shows the same experiment with the oligonucleotides containing the modified bases isoguanine. The tetramolecular structure $(\mathrm{Q})$ predominates in $\mathrm{K}^{+}$, but pentamers (denoted $\mathrm{P}$ ) predominate in other cations shown here. In ammonium ion solution, pentamers and tetramers coexist. Upon cation exchange for ammonium, the expected three inner cations can be either totally replaced $\left(\mathrm{Rb}^{+}\right)$, partly replaced $\left(\mathrm{Cs}^{+}\right)$, or totally preserved $\left(\mathrm{Ba}^{2+}\right)$ in the Ig-modified G4. 
To summarize, the two types of information are provided by mass spectrometry when chemically modified G-quadruplex forming sequences are analyzed: the number of strands and the number of tightly bound cations in each assembly. The expected four-stranded stoichiometries have been confirmed for dTGGGGGT derivatives with single modified bases [39] and for guanine-rich oligonucleotides with modified backbones such as PNA [40, 41]. The pentamers formed by isoguanine derivatives were also expected, owing to the relative orientations of the hydrogen bonds in isoguanine. In contrast, there are instances where mass spectrometry revealed unexpected stoichiometries. For example, the RNA sequence dUAGGGUUAGGGU was found to form a tetramolecular assembly instead of the expected bimolecular species[42]. Higher order assemblies than expected were also revealed for modified oligonucleotides in which the four strands are linked by a trebler linker [43]. In contrast, mass spectrometry sometimes reveals lower than expected strand stoichiometries. For example, the sequences $\mathrm{dTG}_{\mathrm{n}} \mathrm{T}$, usually taken as "prototype" tetramolecular G-quadruplex forming sequences, form tetramolecular structures only for $n$ up to 8 or 9. Longer sequences form trimolecular, bimolecular, or unimolecular structures, depending on G-tract length and cation concentration [44].

The number of cations specifically retained (i.e., the cation binding stoichiometry towards which the adduct distribution is clearly biased) also provides indirect information on the structure because $\mathrm{NH}_{4}{ }^{+}$and $\mathrm{K}^{+}$coordination is only possible between quartets. The ammonium ion count in TGGGGGT variants with modified bases was used to ascertain the number of effective quartets in the tetramolecular structures [43], and this parameter was found to correlate very well with the thermal stability of the tetramolecular assemblies. Detecting the specific number of inner ammonium cations requires specific mass spectrometry instrument tuning to obtain soft conditions [44]. In harsh conditions such as those used in MS/MS, ammonium loss and, at higher energy, strand loss can be observed [34, 46, 47].

The above review focused on mass measurements. A variety of mass spectrometry-related methods have been used to investigate the structure of assemblies in more detail. We wish to make a note on MS/MS and on ion mobility spectrometry techniques. First, MS/MS experiments involve a gas-phase, unimolecular dissociation process, and therefore it is not advisable to make direct comparisons with solution phase stabilities or to attempt to deduce information on the structures without proper theoretical background. With regard to structural characterization of tetramolecular assemblies, ion mobility spectrometry seems the most promising technique. Ion mobility separates ion conformations based on their electrophoretic mobility in a cell filled with gas. As a result, compact and open conformations can be distinguished. This has been used to confirm the presence of tetramers with slipped strands in the self-assembly pathway of dTGGGGGT (see Chapter 5). The ion mobility technique has not yet been applied to modified sequences. 


\section{5. $N M R$}

NMR is a very robust technique that can provide significant information on G4 structure. The preparation of the sample is very easy; there are almost no limitations on salt and buffer composition except that buffers contain only exchangeable protons such as phosphoric acid or deuterated buffers. With the new generation of NMR spectrometer equipped with cryoprobes, one can use very small amounts of material as little as 5 to 10 nanomoles- and there is no need for specific labeling of the oligonucleotides. It is in theory possible to analyse sequences of more than 100 nucleotides in the most favorable cases [48]. In a simple, ${ }^{1} \mathrm{H} 1 \mathrm{D}$ NMR experiment with jump-return water suppression [49], the formation of G4 gives rise to very specific imino proton peaks in the 10-12 ppm region, whereas the formation of Watson-Crick base pairs is usually indicated by lower field peaks between 13 and 14 ppm [50-52].

In the specific case of the very symmetric tetramolecular G4s, all the guanines from the same tetrads are equivalent and will resonate at the same frequency, giving rise to only one peak per tetrad. This is in contrast to the intramolecular G4 structures where each imino proton from each guanine will behave independently with different resonance frequencies in most cases. In the case of the $\mathrm{TG}_{4} \mathrm{~T}$ sequence (Fig. 6) the presence of four sharp peaks is consistent with the formation of a four-layered G4 structure. A great advantage of NMR is its ability to reveal the presence of multiple conformations adopted by the same strand in bulk solution. For instance, when a aTNA nucleotide is inserted at the third position of $\mathrm{TG}_{4} \mathrm{~T}$ sequence (TNA3), the NMR spectrum is more complicated than that of $\mathrm{TG}_{4} \mathrm{~T}$ (Fig. 6); the more crowded imino region of the TNA3 spectrum suggests that several types of quadruplex structures coexist in solution [23]. NMR can also be used to quantify the relative amounts of each conformer by comparing the intensities of the imino peaks signals. The kinetics of interconversion between the different species can also be followed by NMR as shown in Fig.7 for TNA3 and TNA4: We see a difference in the peak intensity ratios when spectra collected after 5 days and after 1 month of incubation are compared. For chemically modified $\mathrm{TG}_{4} \mathrm{~T}$ sequences, the presence of multiple conformations is common. TGGGGT (underlined bases are 8-methyl-2'-deoxyguanosine), TGGGGT (L123, underlined bases are left handed nucleotides modified bases) also exhibit spectra indicative of multiple species $[25,53]$.

To summarize, with a 20 minute acquisition time for a ${ }^{1} \mathrm{H}$ 1D NMR experiment on a 50 nanomole sample, NMR is potentially able to: i) determine whether the oligonucleotide adopts a G4 structure; ii) determine the number of tetrads involved in the G4, and iii) determine the number of conformers in solution, their relative populations, and their interconversion kinetics. 


\section{Stability and kinetics of chemically modified G-quadruplex structures}

\subsection{Stability}

The thermal stability of tetramolecular G4 can be measured by UV, CD, FRET, and NMR. Among these, UV melting method is the most widely used technique, and we have described the procedure in detail in previous reviews [17, 18]. A typical thermal denaturation profile of tetramolecular G4 followed at $295 \mathrm{~nm}$ is shown in Fig. 8A. The process is kinetically irreversible [14], as cooling the sample at the same temperature gradient does not give a superimposable absorbance curve. Hence, this denaturation curve does not reflect an equilibrium process, and thermodynamic parameters cannot be directly extracted from this profile. The apparent melting temperature $\left(T_{1 / 2}\right)$ determined from the denaturation curve strongly depends on the rate of heating. As shown in Fig. 8B, different temperature gradients yield different apparent $T_{1 / 2} \mathrm{~S}$, which further indicates that denaturation profile does not correspond to an equilibrium curve [14]. Interestingly, although this G4 structure involves four strands, the apparent $T_{1 / 2}$ does not depend on concentration [14]. For example, no variation at all of the $T_{1 / 2}$ was observed using different strand concentrations from 5 to $200 \mu \mathrm{M}$ (Fig. 8C). This counter intuitive observation is the result of non-equilibrium melting profiles. With G4 structures, there may be extreme hysteresis at high strand concentrations and a slow rate of annealing, whereas little or no renaturation is observed at low strand concentrations [14-16]. Variations in apparent $T_{1 / 2}$ as a function of heating rate reflect the effects on dissociation $\left(k_{\mathrm{off}}\right)$ as a function of temperature rather than the equilibrium constant. Therefore, when performing experiments to measure the stability of chemically modified tetramolecular G4 structures, one should use the same temperature gradient. Otherwise, incorrect comparisons will arise.

\subsection{Kinetics}

It has been known for over 40 years that the renaturation of short guanine rich oligomers such as G3 is slow [54]. As seen above (Fig. 8A), the reassociation upon cooling of the tetramolecular G4 formed by TGGGGT is very slow at low strand concentration $(20 \mu \mathrm{M})$. Therefore, the association process can be followed at specific wavelengths (typically $295 \mathrm{~nm}$ or $240 \mathrm{~nm}$ ) over time at a constant temperature, and one can obtain association kinetics of the chemically modified structures. In our previous reviews $[17,18]$, we described isothermal renaturation experiments to study the formation of the tetramolecular $\mathrm{G} 4$ in detail. The determination of $k_{\mathrm{on}}$, the association rate constant, requires a determination of the experimental order (see below). The experiments begin with the unfolded species. A time-dependent increase in absorbance at $295 \mathrm{~nm}$ and a time-dependent decrease in absorbance at $240 \mathrm{~nm}$ 
indicate G-quadruplex formation (Fig. 9A). Techniques such as circular dichroism, fluorescence, and NMR also can be used to follow the association process. The details of kinetic analysis have been described before and will not be repeated here $[17,18]$. Herein, we would like to emphasis two points concerning chemically modified sequences.

The first is the reaction order. The order of the reaction " $n$ " may be experimentally estimated by analyzing the concentration dependency of the association process. In fact, we [14] and others [16] found an experimental order of between 3 and 4 for the association rate with respect to strand concentration. The fourth reaction order is in agreement with the results obtained by size exclusion chromatography method [15], and the data agree with this value in most cases. One study indicated that association of tetramolecular G4 by LNA is a second order reaction, not fourth [55]. In fact, an NMR investigation also found a slightly lower experimental value for $n$, closer to 3, for the LNA [56]. Thus, the exact value of the reaction order may depend on sequence and ionic conditions. NMR and ESI-MS allow one to follow the association process in a more precise manner than absorbance or CD: These techniques reveal the existence of "imperfect" tetramolecular complexes, in which the strands are not aligned. These complexes may be long-lived, and their final conversion into the canonical quadruplex may take weeks or months $[38,56]$.

The second note is in regards to the initial experimental strand concentration of chemically modified sequences. As described above, the reaction order is near 4, therefore, the strong dependency on strand concentration results in practical implications: An increase in concentration of 10-fold will increase the apparent association reaction from too slow to be measured to a rate too fast to be followed [15]. For example, for the hexitol modified sequence TGGGGT (underlined G indicates modification), when the concentration is $20 \mu \mathrm{M}$, association is very rapid and data cannot be fitted well $(\mathrm{R}=0.95$; Fig. 9B). When the concentration is $10 \mu \mathrm{M}$ (a two-fold decrease) the association reaction can be monitored by following the absorbance change [23]. In fact, in addition to concentration, changes in the temperature or the ionic strength or the presence of chaperone molecules (proteins, small ligands, and polymers) affect the association rate $[14,17,18]$.

Recently, we reviewed the effects of chemical modifications on structure, stability, and kinetics on tetramolecular G4 [Zhou et al, manuscript in preparation]. We found that modification of every part of the nucleic acid strand, guanine base, sugar, phosphate and even strand polarity, altered the properties of G4 structures.

\section{Self-assembly pathway of tetramolecular G-quadruplexes}

In our previous paper, we reviewed the association pathway of tetramolecular G4 by unmodified sequences [18, and references therein]. Herein, we give a brief 
introduction of this and focus on chemically modified sequences. As shown in Fig. 10, molecular dynamic simulations indicate that the association of tetramolecular G4 might have several stable intermediate states [57]: (I) monomers, (II) two-stranded states (dimers), (III) dimer plus a third strand (trimers), and (IV) ultimately the slowly forming four-stranded structure (tetramers). Evidence for these states comes from mass and NMR spectrometry [38,56]. Interestingly, five-stranded species (pentamers) were also observed by mass spectrometry, and rearrangement of slipped strands to form canonical tetramolecular G4 is extremely slow. For instance, the process may last more than 4 months at $4^{\circ} \mathrm{C}[38]$.

Chemically modifications may sometimes result in very slow G4 formation. For example, the CD spectra of TGGGGT and TGGGGT (underlined bases are 8-methylguanine) collected after a 2-day incubation are different from the ones measured after 1 month at $4^{\circ} \mathrm{C}$ [30]. Furthermore, a position-dependent phenomenon is observed. For instance, we recently analyzed the effect of substituting guanines in TGGGGT by aTNA, and found that the substitution at the first and second guanine positions leads to well-defined tetramolecular G4 in five days. However, when modifications are made at the third and fourth positions, NMR spectra demonstrate that the corresponding tetramolecular $\mathrm{G} 4$ are not fully assembled even after one month at $4^{\circ} \mathrm{C}$ (Fig. 7) [23].

\section{Higher order structures based on tetramolecular G-quadruplexes}

Short guanine rich sequences can form octamers (dimmers of tetramolecular G4) under certain conditions. For example, it has been demonstrated that there are two G4 species formed by $\mathrm{d}(\mathrm{GGGT})$ that can be selectively controlled by an appropriate preparation protocol. The higher order octamers are formed by the association of interlocked slipped strands or by end-to-end stacking [58]. Recently, a work indicated that the sequence dCGGTGGT forms an octamer through the $5^{\prime}-5^{\prime}$ stacking of two tetramolecular G4 subunits via unusual $\mathrm{G}(: \mathrm{C}): \mathrm{G}(: \mathrm{C}): \mathrm{G}(: \mathrm{C}): \mathrm{G}(: \mathrm{C})$ octads [59]. Interestingly, some higher order structures such as G-wires and frayed wires can be formed with short guanine-rich sequences. These higher order structures are described in detail by us [17] and others [60]. Herein, we just introduce these structures briefly and focus on chemically modified higher ordered structures.

As shown in Fig. 11, G-wires [61-63] and frayed wires [64,65] are the supramolecular structures assembled by a number of guanine-rich sequences. The difference between G-wires and frayed wires is that the latter has two flexible tails $\left(\mathrm{A}_{15} / \mathrm{T}_{15}\right)$ that radiate from the guanine core. Parameters including type and concentration of cations and temperature affect the self-assembly of these higher order structures [60]. Interestingly, chemical modifications not only affect the properties of tetramolecular G4s but also play a role in the assembly of higher ordered structures. For example, the presence of $5^{\prime}$ phosphate groups inhibits G-wire formation. Furthermore, modified G-wires with 2,2'-bipyridine units instead of 
thymines as ind- $\mathrm{G}_{4} \mathrm{~T}_{4} \mathrm{G}_{4}$ allow one to control $\mathrm{G}$-wire switching by external signals. For example, alternating addition of $\mathrm{Ni}^{2+}$ and $\mathrm{Na}_{2}$ EDTA can cycle the G-wire between higher order and disorganized structures [66]. For frayed wires, incorporation of the isoelectronic guanine analog pyrazolo[3,4,-d]pyrimidine (PPG) into $d\left(A_{15} \mathrm{G}_{15}\right)$ inhibits wire formation [67].

These higher order structures can be characterized several ways:

i) Non-denaturing gel electrophoresis. One can simply adjust acrylamide concentration to allow complexes of larger size to enter the gel. Very large wires may require using agarose as one cannot obtain reliable gels with acrylamide content below $4 \%$

ii) Electrospray mass spectrometry: Quadruplex dimers, trimers, and higher order structures of moderate size may be analyzed by ESI-MS. For example, octamers (dimers of tetramolecular G-quadruplexes) were characterized by ESI-MS [59]. However, polydisperse complexes such as G-wires cannot be characterized by ESI-MS techniques.

iii) Atomic force microscopy (AFM) and electron microscopy (EM): AFM and EM are the techniques of choice to analyze large complexes. G-wires may reach several $\mu \mathrm{m}$ in length and AFM provides information on length distribution, stiffness, and height.

\section{Conclusions}

In this review, we introduced several commonly used biophysical methods to investigate tetramolecular DNA G4s and their higher order structures containing chemical modifications. Chemical modifications to base, sugar, or backbone may lead to unexpected behaviors that are quite different from that of the natural sequences. Methods still need to be developed to further investigate this topic. Furthermore, some modifications result in the formation of a mixture of G4 species, and we do not know the exact structure of each conformation. Important efforts remain to be made concerning chemically modified tetramolecular G4. We hope this review allows one to understand how to design new structures and perform experiments to characterize these structures and their stabilities and kinetics.

\section{Acknowledgements}

Jun Zhou is the recipient of a Marie Curie International Incoming Fellowship. This work was supported by grants from ANR (G4 Toolbox, F-DNA and Oligoswitch) and Conseil Régional d'Aquitaine ("Chaire d'accueil") to J.L. Mergny. 


\section{References}

[1] M. Gellert, M.N. Lipsett, D.R. Davies, Helix formation by guanylic acid. Proc. Natl. Acad. Sci. USA 48 (1962) 2013-2018.

[2] D. Sen, W. Gilbert, Formation of parallel 4-stranded complexes by guanine-rich motifs in DNA and its implications for meiosis. Nature 334 (1988) 364-366.

[3] J.R. Williamson, G-tetrad structures in telomeric DNA. Ann. Rev. Biophys. Biomol. Struct. 23 (1994) 703-730.

[4] J.L. Huppert, Four-stranded nucleic acids: structure, function and targeting of G-quadruplexes. Chem. Soc. Rev. 37 (2008) 1375-1384.

[5] A.K. Todd, M. Johnston, S. Neidle, Highly prevalent putative quadruplex sequence motifs in human DNA. Nucleic Acids Res. 33 (2005) 2901-2907.

[6] J.L. Huppert, S. Balasubramanian, Prevalence of quadruplexes in the human genome. Nucleic Acids Res. 33 (2005) 2908-2916.

[7] G. Biffi, D. Tannahill, J. McCafferty, S. Balasubramanian, Quantitative visualization of DNA G-quadruplex structures in human cells. Nat. Chem. 5 (2013) $182-186$.

[8] J.T. Davis, G-quartets 40 years later: from 5'-GMP to molecular biology and supramolecular chemistry. Angew. Chem. Int. Ed. 43 (2004) 668-698.

[9] P. Alberti, A. Bourdoncle, B. Saccà, L. Lacroix, J.L. Mergny, DNA nanomachines and nanostructures involving quadruplexes. Org. Biomol. Chem. 4 (2006) 33833391.

[10] J.T. Davis, G.P. Spada, Supramolecular architectures generated by self-assembly of guanosine derivatives. Chem. Soc. Rev. 36 (2007) 296-313.

[11] Y. Krishnan, F.C. Simmel. Nucleic acid based molecular devices, Angew. Chem. Int. Ed. 50 (2011) 3124-3156.

[12] S. Burge, G.N. Parkinson, P. Hazel, A.K. Todd, S. Neidle, Quadruplex DNA: sequence, topology and structure. Nucleic Acids Res. 34 (2006) 5402-5415.

[13] J. Zhou, A. Bourdoncle, F. Rosu, V. Gabelica, J.L. Mergny, Tri-G-quadruplex: controlled assembly of a G-quadruplex structure from three G-rich strands. Angew. Chem. Int. Ed. 51 (2012) 11002-11005.

[14] J.L. Mergny, A. De Cian, A. Ghelab, B. Saccà, L. Lacroix, Kinetics of tetramolecular quadruplexes. Nucleic Acids Res. 33 (2005) 81-94.

[15] J.R. Wyatt, P.W. Davis, S.M. Freier, Kinetics of G-quartet-mediated tetramer formation. Biochemistry 35 (1996) 8002-8008.

[16] L. Petraccone, B. Pagano, V. Esposito, A. Randazzo, G. Piccialli, G. Barone, C.A. Mattia, C. Giancola, Thermodynamics and kinetics of PNA-DNA quadruplex-forming chimeras. J. Am. Chem. Soc. 127 (2005) 16215-16223.

[17] J.L. Mergny, J. Gros, A. De Cian, A. Bourdoncle, F. Rosu, B. Saccà, L. Guittat, S. Amrane, M. Mills, P. Alberti, M. Takasugi, L. Lacroix. Energetics, kinetics and dynamics of quadruplex folding. In: S. Neidle, S. Balasubramanian, eds. Quadruplex Nucleic Acids. Cambridge, UK: The Royal Society of Chemistry, 2006: pp. 31-80.

[18] P.L.T. Tran, A. De Cian, J. Gros, R. Moriyama, J.L. Mergny, Tetramolecular 
quadruplex stability and assembly. Top Curr. Chem. 330 (2013) 243-273.

[19] S. Paramasivan, I. Rujan, P.H. Bolton, Circular dichroism of quadruplex DNAs: applications to structure, cation effects and ligand binding. Methods 43 (2007) 324-331.

[20] J. Kypr, I. Kejnovská, D. Renčiuk, M. Vorlíčková, Circular dichroism and conformational polymorphism of DNA. Nucleic Acids Res. 37 (2009) 1713-1725.

[21] M. Vorlíčková, I. Kejnovská, J. Sagi, D. Renčiuk, K. Bednářová, J. Motlová, J. Kypr, Circular dichroism and guanine quadruplexes. Methods 57 (2012) 64-75.

[22] A. Randazzo, G.P. Spada, M. Webba da , Circular dichroism of quadruplex structures. Top Curr. Chem. 330 (2013) 67-86.

[23] J. Zhou, K. Murayama, S. Amrane, H. Kashida, A. Bourdoncle, H. Asanuma, J.L. Mergny. The "sugar-deficient" G-quadruplex: incorporation of aTNA in quadruplex structures. Chem. Sci. 4 (2013) 3693-3698.

[24] V. Esposito, A. Virgilio, A. Randazzo, A. Galeone, L. Mayol, A new class of DNA quadruplexes formed by oligodeoxyribonucleotides containing a $3^{\prime}-3^{\prime}$ or $5^{\prime}-5^{\prime}$ inversion of polarity site. Chem. Commun. 31 (2005) 3953-3955.

[25] A. Virgilio, V. Esposito, G. Citarella, A. Pepe, L. Mayol, A. Galeone, The insertion of two 8-methyl-2'-deoxyguanosine residues in tetramolecular quadruplex structures: trying to orientate the strands. Nucleic Acids Res. 40 (2012) 461-475.

[26] S. Masiero, R. Trotta, S. Pieraccini, S. De Tito, R. Perone, A. Randazzo, G.P. Spada, A non-empirical chromophoric interpretation of CD spectra of DNA G-quadruplex structures. Org. Biomol. Chem. 8 (2010) 2683-2692.

[27] J.L. Mergny, A.T. Phan, L. Lacroix, Following G-quartet formation by UV-spectroscopy. FEBS Lett. 435 (1998) 74-78.

[28] J.L. Mergny, J. Li, L. Lacroix, S. Amrane, J.B. Chaires, Thermal difference spectra: a specific signature for nucleic acid structures, Nucleic Acids Res. 33 (2005) e138.

[29] A.I. Karsisiotis, N.M. Hessari, E. Novellino, G.P. Spada, A. Randazzo, M. Webba da Silva, Topological characterization of nucleic acid G-quadruplexes by UV absorption and circular dichroism. Angew. Chem. Int. Ed. 50 (2011) 10645 10648.

[30] P.L.T. Tran, A. Virgilio, V. Esposito, G. Citarella, J.L. Mergny, A. Galeone, Effects of 8-methylguanine on structure, stability and kinetics of formation of tetramolecular quadruplexes. Biochimie 93 (2011) 399-408.

[31] N. Tretyakova, P.W. Villalta, S. Kotapati, Mass spectrometry of structurally modified DNA. Chem. Rev. 113 (2013) 2395-2436.

[32] G. Yuan, Q. Zhang, J. Zhou, H. Li, Mass spectrometry of G-quadruplex DNA: Formation, recognition, property, conversion, and conformation. Mass Spectrom. Rev. 30 (2011) 1121-1142.

[33] D.R. Goodlett, D.G. Camp, II, C.C. Hardin, M. Corregan, R.D. Smith, Direct observation of a DNA quadruplex by electrospray ionization mass spectrometry. Biol. Mass Spectrom. 22 (1993) 181-183.

[34] F. Rosu, V. Gabelica, C. Houssier, P. Colson, E. De Pauw, Triplex and quadruplex DNA structures studied by electrospray mass spectrometry. Rapid 
Commun. Mass Spectrom. 16 (2002) 1729-1736.

[35] S.E. Evans, M.A. Mendez, K.B. Turner, L.R. Keating, R.T. Grimes, S. Melchoir, V.A. Szalai, End-stacking of copper cationic porphyrins on parallel-stranded guanine quadruplexes. J. Biol. Inorg. Chem. 12 (2007) 1235-1249.

[36] S.E. Pierce, J. Wang, J. Jayawickramarajah, A.D. Hamilton, J.S. Brodbelt, Examination of the Effect of the Annealing Cation on Higher Order Structures Containing Guanine or Isoguanine Repeats. Chem. Eur. J. 15 (2009) 1124411255.

[37] R. Ferreira, A. Marchand, V. Gabelica, Mass spectrometry and ion mobility spectrometry of G-quadruplexes. A study of solvent effects on dimer formation and structural transitions in the telomeric DNA sequence d(TAGGGTTAGGGT). Methods 57 (2012) 56-63.

[38] F. Rosu, V. Gabelica, H. Poncelet, E. De Pauw, Tetramolecular G-quadruplex formation pathways studied by electrospray mass spectrometry. Nucleic Acids Res 38 (2010) 5217-5225.

[39] J. Gros, F. Rosu, S. Amrane, A. De Cian, V. Gabelica, L. Lacroix, J.L. Mergny, Guanines are a quartet's best friend: impact of base substitutions on the kinetics and stability of tetramolecularquadruplexes. Nucleic Acids Res. 35 (2007) 30643075.

[40] B. Datta, M.E. Bier, S. Roy, B.A. Armitage, Quadruplex formation by a guanine-rich PNA oligomer. J. Am. Chem. Soc. 127 (2005) 4199-4207.

[41] Y. Krishnan-Ghosh, E. Stephens, S. Balasubramanian, A PNA 4 quadruplex. J. Am. Chem. Soc. 126 (2004) 5944-5945.

[42] G.W. Collie, G.N. Parkinson, S. Neidle, F. Rosu, E. De Pauw, V. Gabelica, Electrospray mass spectrometry of telomeric RNA (TERRA) reveals the formation of stable multimeric G-quadruplex structures. J. Am. Chem. Soc. 132 (2010) 9328-9334.

[43] R. Ferreira, M. Alvira, A. Avino, I. Gomez-Pinto, C. Gonzalez, V. Gabelica, R. Eritja, Synthesis and structural characterization of stable branched DNA G-quadruplexes using the treblerphosphoramidite. Chem. Open 1 (2012) 106-114

[44] L. Joly, F. Rosu, V. Gabelica, d(TGnT) DNA sequences do not necessarily form tetramolecular G-quadruplexes. Chem. Commun. 48 (2012) 8386-8388.

[45] F. Balthasart, J. Plavec, V. Gabelica, Ammonium ion binding to DNA G-quadruplexes: do electrospray mass spectra faithfully reflect the solution-phase species? J. Am. Soc. Mass Spectrom. 24 (2013) 1-8

[46] L. Mazzitelli, J. Wang, S.I. Smith, J.S. Brodbelt, Gas-phase stability of G-quadruplex DNA determined by electrospray ionization tandem mass spectrometry and molecular dynamics simulations. Int. J. Am. Soc. Mass Spectrom. 18 (2007) 1760-1773.

[47] K.C. Porter, J.L. Beck, Assessment of the gas phase stability of quadruplex DNA using travelling wave ion mobility mass spectrometry. J. Mass Spectrom. 304 (2011) 195-203.

[48] S. Amrane, M. Adrian, B. Heddi, A. Serero, A. Nicolas, J.L. Mergny, A.T. Phan, Formation of pearl-necklace monomorphic G-quadruplexes in the human CEB25 
minisatellite. J. Am. Chem. Soc. 134 (2012) 5807-5816.

[49] P. Plateau, M. Guéron, Exchangeable proton NMR without base-line distorsion, using new strong-pulse sequences. J. Am. Chem. Soc., 104 (1982) 7310-7311.

[50] J. Feigon, K.M. Koshlap, F.W. Smith, ${ }^{1}$ H NMR spectroscopy of DNA triplexes and quadruplexes. Methods Enzymol. 261 (1995) 225-255.

[51] M. Webba da Silva, NMR methods for studying quadruplex nucleic acids. Methods 43 (2007) 264-277.

[52] M. Adrian, B. Heddi, A.T. Phan, NMR spectroscopy of G-quadruplexes. Methods 57 (2012) 11-24.

[53] A. Virgilio, V. Esposito, G. Citarella, A. Mangoni, L. Mayol, A. Galeone, Unprecedented right- and left-handed quadruplex structures formed by heterochiral oligodeoxyribonucleotides. Biochimie 93 (2011) 1193-1196.

[54] R.K. Ralph, W.J. Connors, H.G. Khorana, Secondary structure and aggregation in deoxyguanosine oligonucleotides. J. Am. Chem. Soc. 84 (1962) 2265-2266.

[55] L. Petraccone, E. Erra, A. Randazzo, C. Giancola, Energetic aspects of locked nucleic acids quadruplex association and dissociation. Biopolymers 83 (2006) 584-594.

[56] C. Bardin, J.L. Leroy, The formation pathway of tetramolecular G-quadruplexes. Nucleic Acids Res 36 (2008) 477-488.

[57] R. Stefl, T.E. Cheatham, N. Spacková, E. Fadrná, I. Berger, J. Koca, J. Sponer, Formation pathways of a guanine-quadruplex DNA revealed by molecular dynamics and thermodynamic analysis of the substates. Biophys. J 85 (2003) 17871804.

[58] Y. Krishnan-Ghosh, D. Liu, S. Balasubramanian, Formation of an interlocked quadruplex dimer by d(GGGT). J. Am. Chem. Soc. 126 (2004) 11009-11016.

[59] N. Borbone, J. Amato, G. Oliviero, V. D’Atri, V. Gabelica, E. De Pauw, G. Piccialli, L. Mayo, d(CGGTGGT) forms an octameric parallel G-quadruplex via stacking of unusual G(:C):G(:C):G(:C):G(:C) octads. Nucleic Acids Res. 39 (2011) 7848-7857.

[60] T.C. Marsh, Z.M. Henseler, M.A. Klimstra, Morphological heterogeneity of supramolecular G-DNA polymers derived from guanine rich oligonucleotides. In: W. Fritzsche, L.Spindler, eds. Guanine Quartets: Structure and Application. Cambridge, UK: The Royal Society of Chemistry, 2013: pp. 48-62.

[61] T.C. Marsh, E. Henderson, G-wires: self-assembly of a telomeric oligonucleotide, d(GGGGTTGGGG), into large superstructures. Biochemistry 33 (1994) 1071810724.

[62] S. Lyonnais, O. Piétrement, A. Chepelianski, S. Guéron, L. Lacroix, E. Le Cam, J.L. Mergny, Functionalization of DNA G-wires for patterning and nanofabrication. Nucleic Acids SympSer (Oxf) 52 (2008) 689-690.

[63] A.B. Kotlyar, N. Borovok, T. Molotsky, L. Fadeev, M. Gozin, In vitro synthesis of uniform poly $(\mathrm{dG})$-poly $(\mathrm{dC})$ by Klenowexo-fragment of polymerase I. Nucleic Acids Res 33 (2005) 525-535.

[64] E. Protozanova, R.B. Macgregor Jr, Frayed wires: a thermally stable form of DNA with two distinct structural domains. Biochemistry 35(1996) 16638-16645. 
[65] M.A. Batalia, E. Protozanova, R.B. Macgregor Jr, D.A. Erie, Self-assembly of frayed wires and frayed-wire networks: nanoconstruction with multistranded DNA. Nano Lett. 2 (2002) 269-274.

[66] D. Miyoshi, H. Karimata, Z. Wang, K. Koumoto, N. Sugimoto, Artificial G-wire switch with 2,2'-bipyridine units responsive todivalent metal ions. J. Am. Chem. Soc. 129 (2007) 5919-5925.

[67] R.M. Abu-Ghazalah, J. Irizar, A.S. Helmy, R.B. Macgregor Jr, A study of the interactions that stabilize DNA frayed wires. Biophys. Chem. 147 (2010) 123-129. 


\section{Figure legends:}

\section{Figure 1}

(A) G-quartet structure and schematic illustration of a parallel tetramolecular G-quadruplex. (B) Three-dimensional rendering of a parallel tetramolecular G-quadruplex (PDB: 2GW0).

\section{Figure 2}

(A) CD spectra of $\mathrm{TG}_{4} \mathrm{~T}$ and aTNA substituted samples TNA1 and TNA3 in $100 \mathrm{mM}$ $\mathrm{K}^{+}$. Spectra were recorded at $20^{\circ} \mathrm{C}$. Insert is the chemical structure of an acyclic threoninol nucleic acid (aTNA). (B) CD spectra of TNA3 at $20^{\circ} \mathrm{C}$ and $70^{\circ} \mathrm{C}$ (reproduced from ref. [23], by permission of The Royal Chemical Society).

\section{Figure 3}

(A) Isothermal difference spectra (IDS) and (B) thermal difference spectra (TDS) of natural sequences and aTNA modified sequences. IDS were calculated from the difference between the absorbance recorded at $10^{\circ} \mathrm{C}$ before and after kinetic experiments in $10 \mathrm{mM}$ lithium cacodylate (pH 7.0), $500 \mathrm{mM} \mathrm{KCl}$. TDS were obtained from the difference between the absorbance recorded at high temperature and that recorded at low temperature in $10 \mathrm{mM}$ lithium cacodylate $(\mathrm{pH} \mathrm{7.0)}, 100 \mathrm{mM} \mathrm{KCl}$ (reproduced from ref. [23], by permission of The Royal Chemical Society).

\section{Figure 4}

PAGE behavior of G-quadruplexes containing chemically modified bases (A) 8-methylguanineand (B) acyclic threoninol nucleic acid on a non-denaturing 20\% acrylamide gel. (Panel A reproduced from ref. [30], with permission from Elsevier).

\section{Figure 5}

ESI-mass spectra of (A) dTGGGGTTTT and (B) dTIgIgIgIgTTTT after annealing at $100-125 \mu \mathrm{M}$ single strand in a $440 \mathrm{mM}$ solution of the salt noted in the spectra. Immediately before ESI-MS analysis, all solutions except those containing ammonium acetate were desalted using 5-kDa molecular weight centrifugal filters. After desalting, ammonium acetate (50 mm final concentration) and methanol $(20 \%$ by volume) were added no more than two minutes before ESI-MS analysis. Q refers to a four-stranded assembly, $\mathrm{P}$ to a five-stranded assembly, and SS denotes the single strand (reprinted from reference [36] with the permission of Wiley \& Sons).

\section{Figure 6}

Example of the imino regions of the ${ }^{1} \mathrm{H}$ NMR spectra of a natural G-quadruplex and G-quadruplexes containing aTNA modified bases at $25^{\circ} \mathrm{C}$ (reproduced from ref. [23], by permission of The Royal Chemical Society). NMR experiments were performed using $250 \mu \mathrm{M}$ oligonucleotide in $10 \mathrm{mM}$ potassium phosphate buffer ( $\mathrm{pH} 7.0$ ) containing $100 \mathrm{mMKCl}$. 


\section{Figure 7}

Imino region of ${ }^{1} \mathrm{H}$ NMR spectra of TNA3 and TNA4 collected after 5 days or 1 month (reproduced from ref. [23], by permission of The Royal Chemical Society).

\section{Figure 8}

(A) Example of an irreversible melting curve of G-quadruplex formed by TGGGGT in $0.11 \mathrm{M} \mathrm{Na}^{+}$recorded at $295 \mathrm{~nm}$ with a temperature gradient of $\sim 0.18{ }^{\circ} \mathrm{C} / \mathrm{min}$. Arrows indicate directions of temperature changes. (B) $T_{1 / 2}$ of the G-quadruplex formed by TGGGGT as a function of the average temperature gradient. (C) Dependence of the $T_{1 / 2}$ value of the G-quadruplex formed by TGGGGT on the strand concentration between $5 \mu \mathrm{M}$ and $200 \mu \mathrm{M}$ (reproduced from ref. [14], by permission of Oxford University Press).

\section{Figure 9}

(A) Example of an isothermal association experiment followed by absorbance. Two different wavelengths were followed: $240 \mathrm{~nm}$ (empty circles, values shown on the left Y-scale) and $295 \mathrm{~nm}$ (black circle, values shown on the right right) (reproduced from ref. [18], by permission of Springer). (B) Example of a fast association processthat cannot be fitted well $(\mathrm{R}=0.953)$.

\section{Figure 10}

Potential association pathway of tetramolecular quadruplexes (reproduced from ref. [18], by permission of Springer).

\section{Figure 11}

Models of a G-wire and a frayed wire. 


\section{Figure 1}
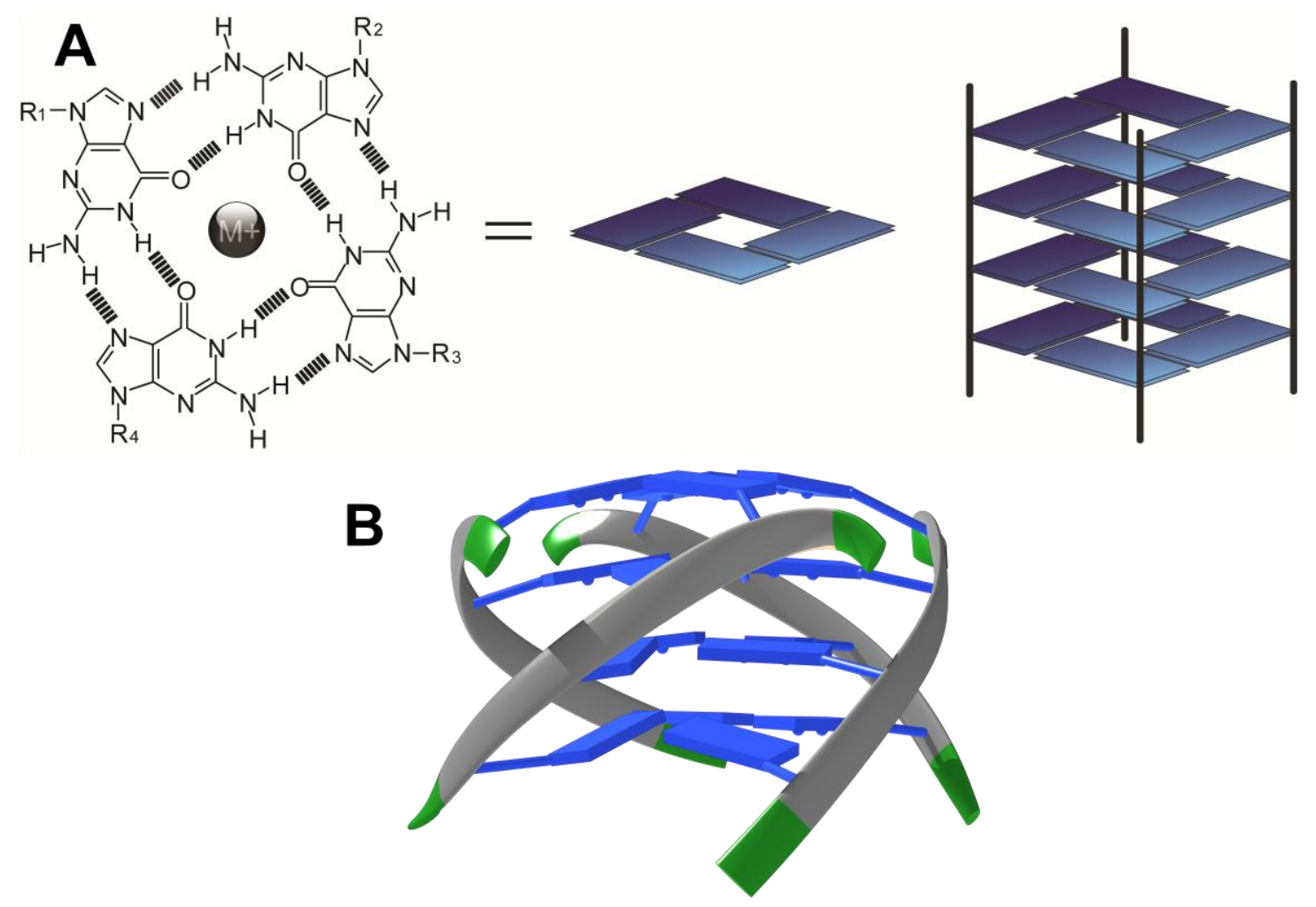
Figure 2
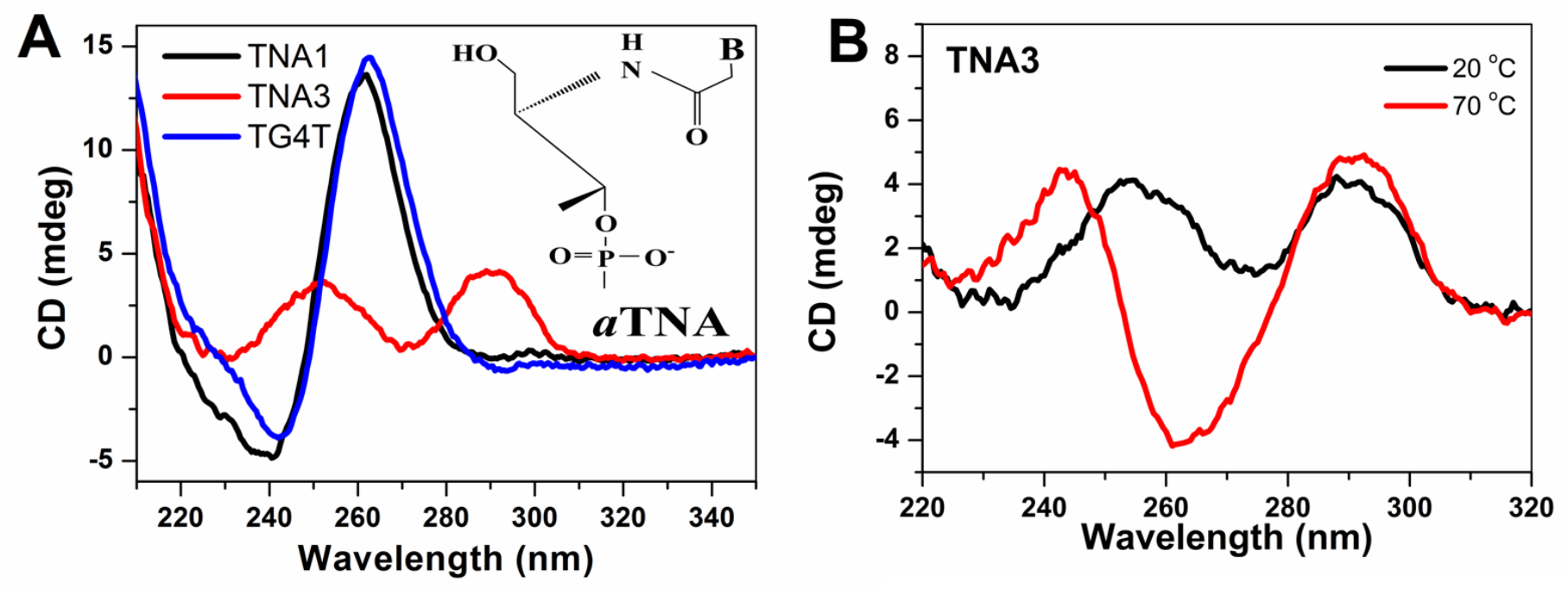
Figure 3

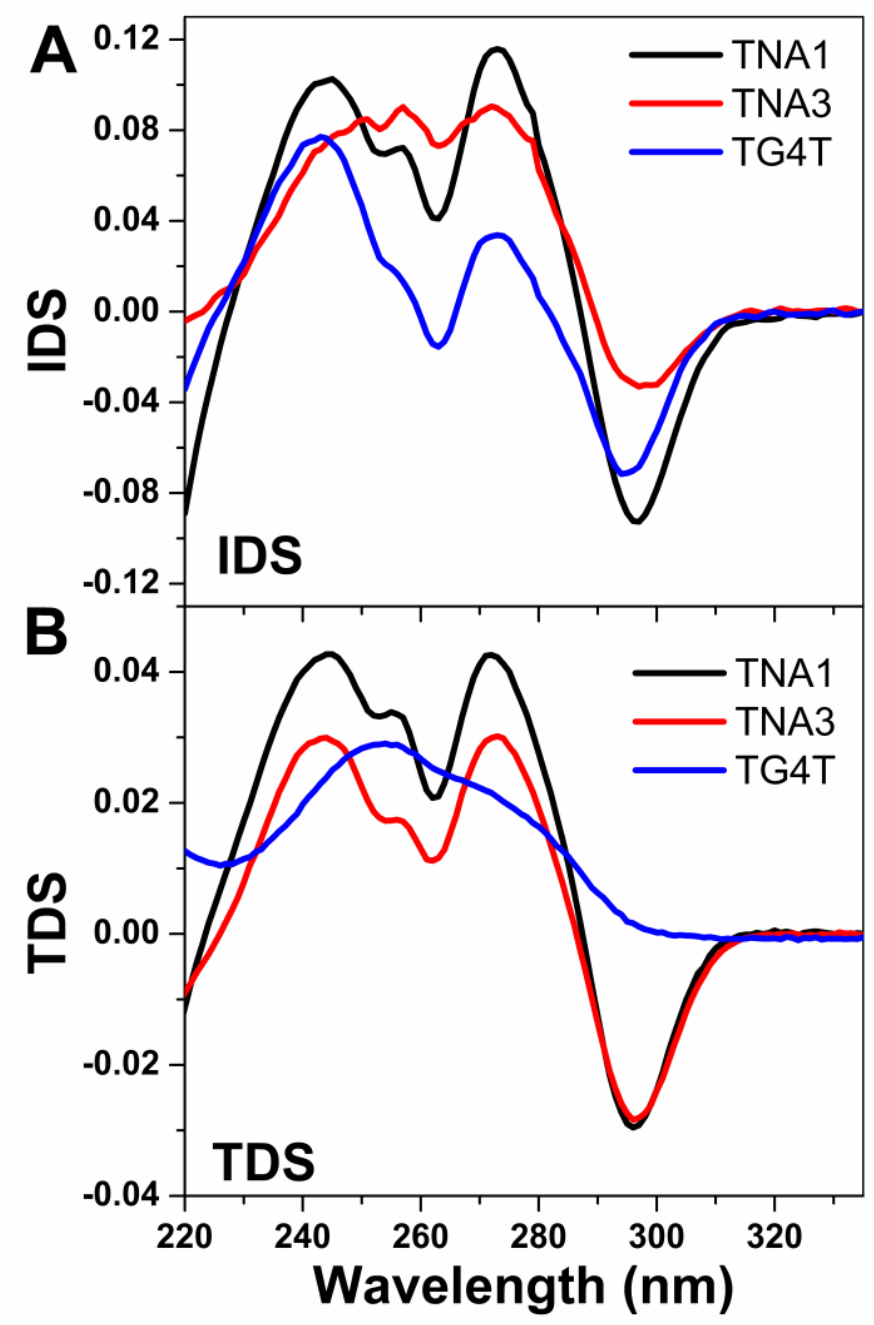




\section{Figure 4}

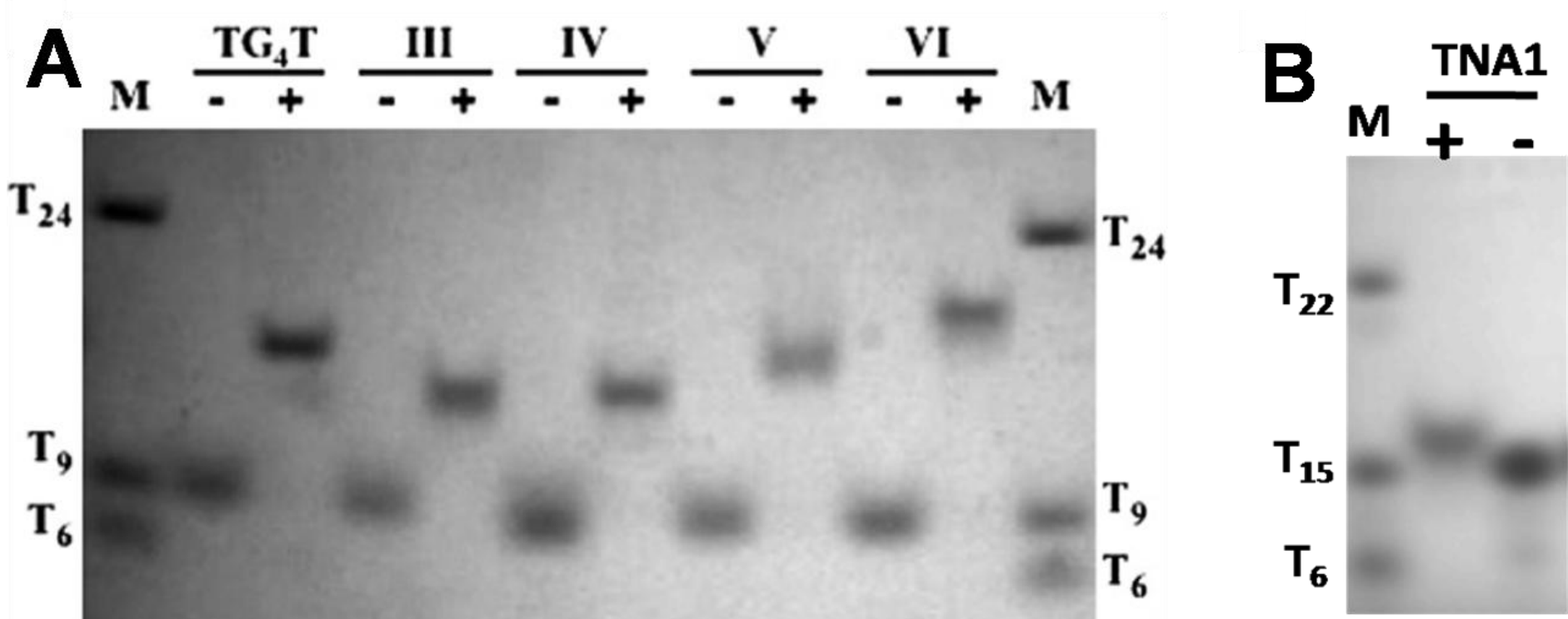




\section{Figure 5}

(A) dTGGGGTTTT

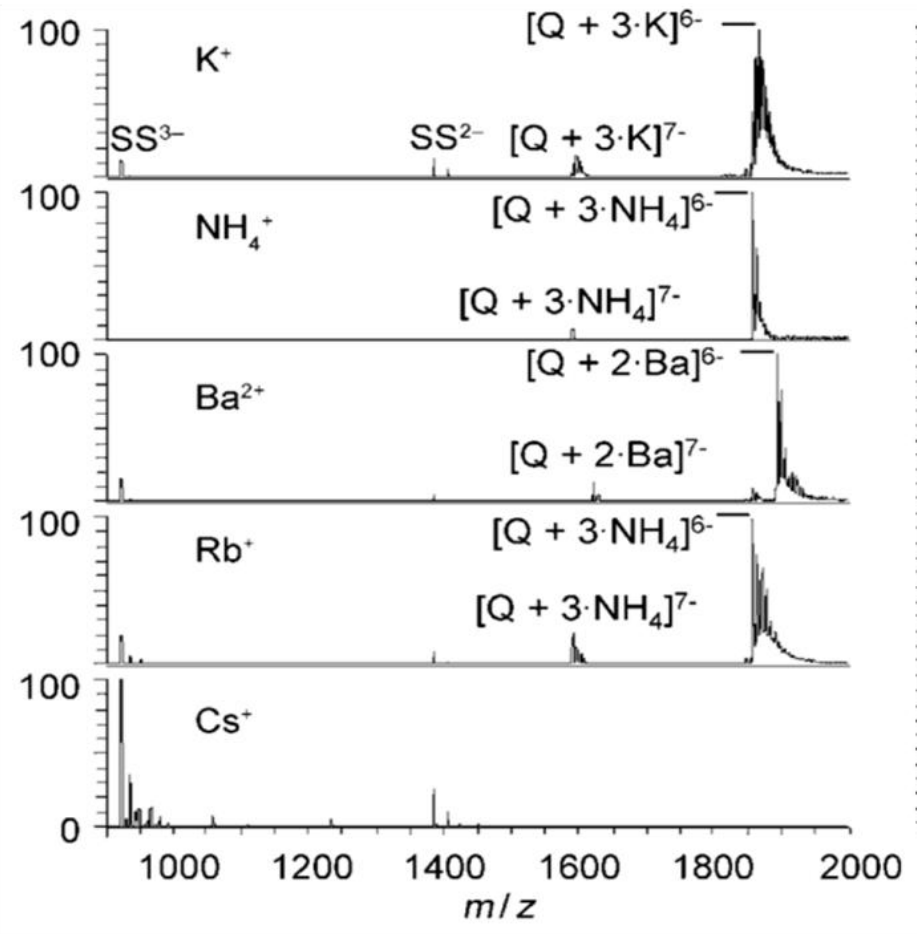

(B) dTIglglglgTTTT

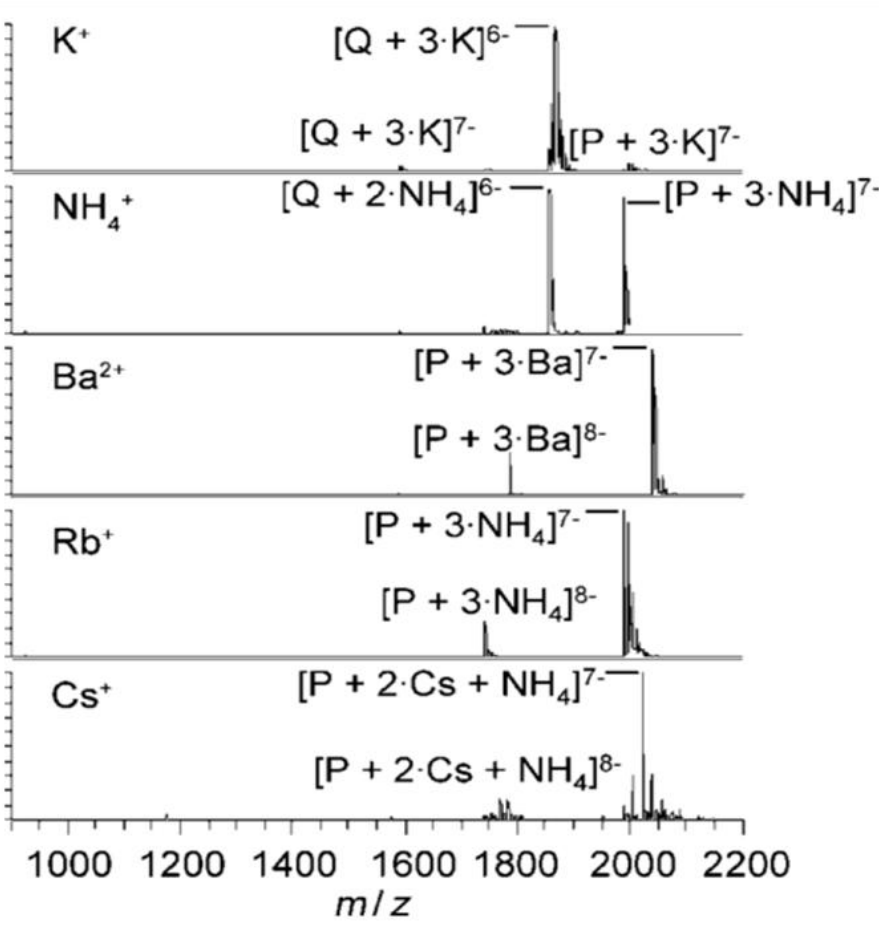




\section{Figure 6}

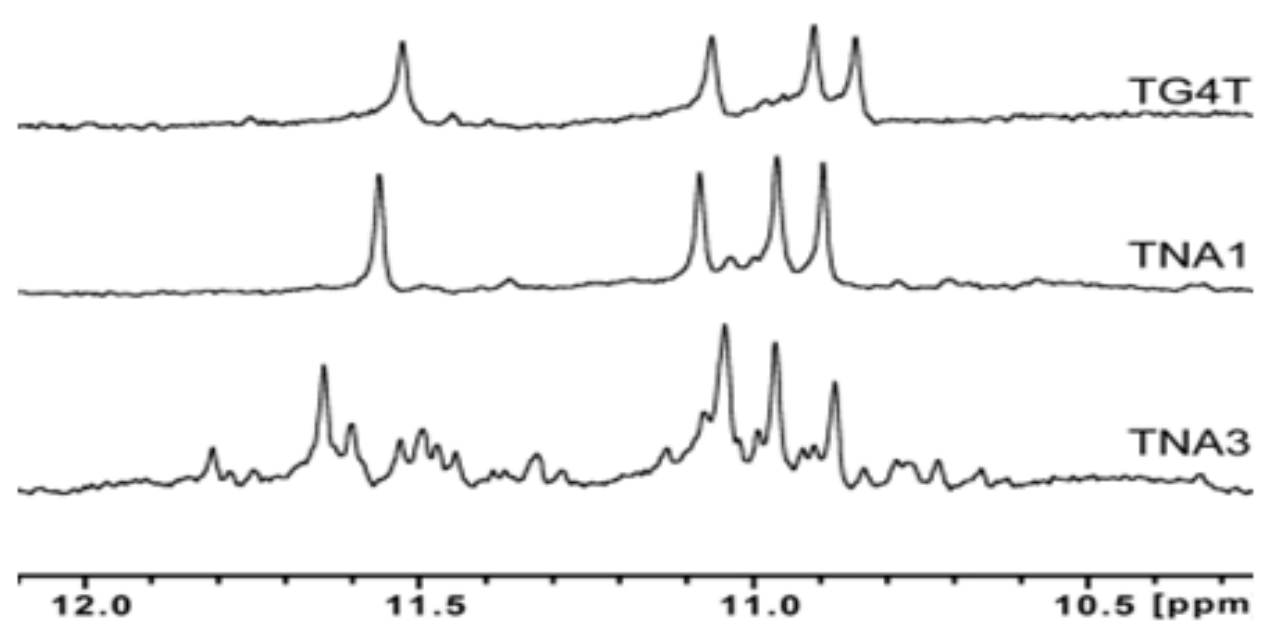




\section{Figure 7}

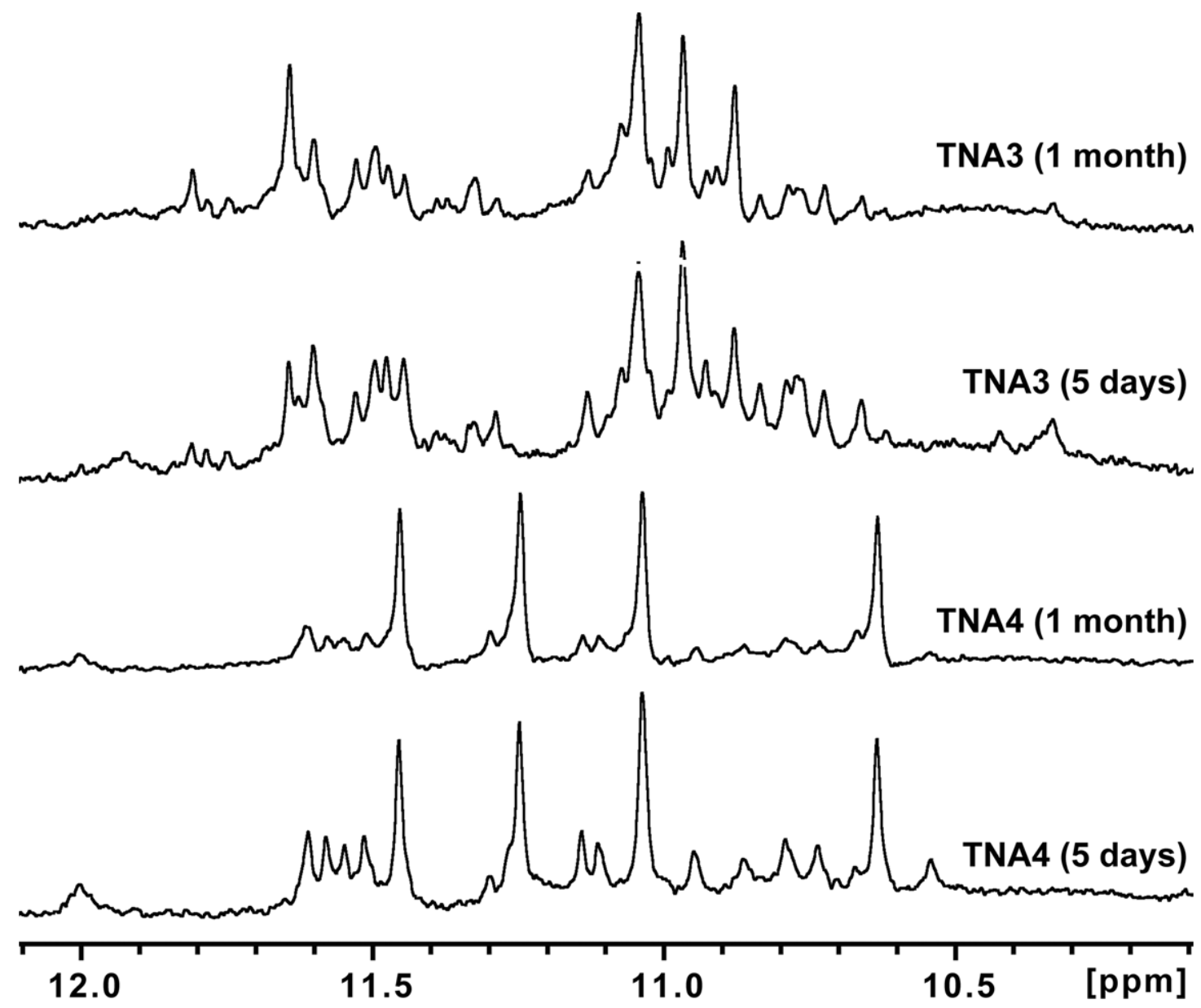




\section{Figure 8}

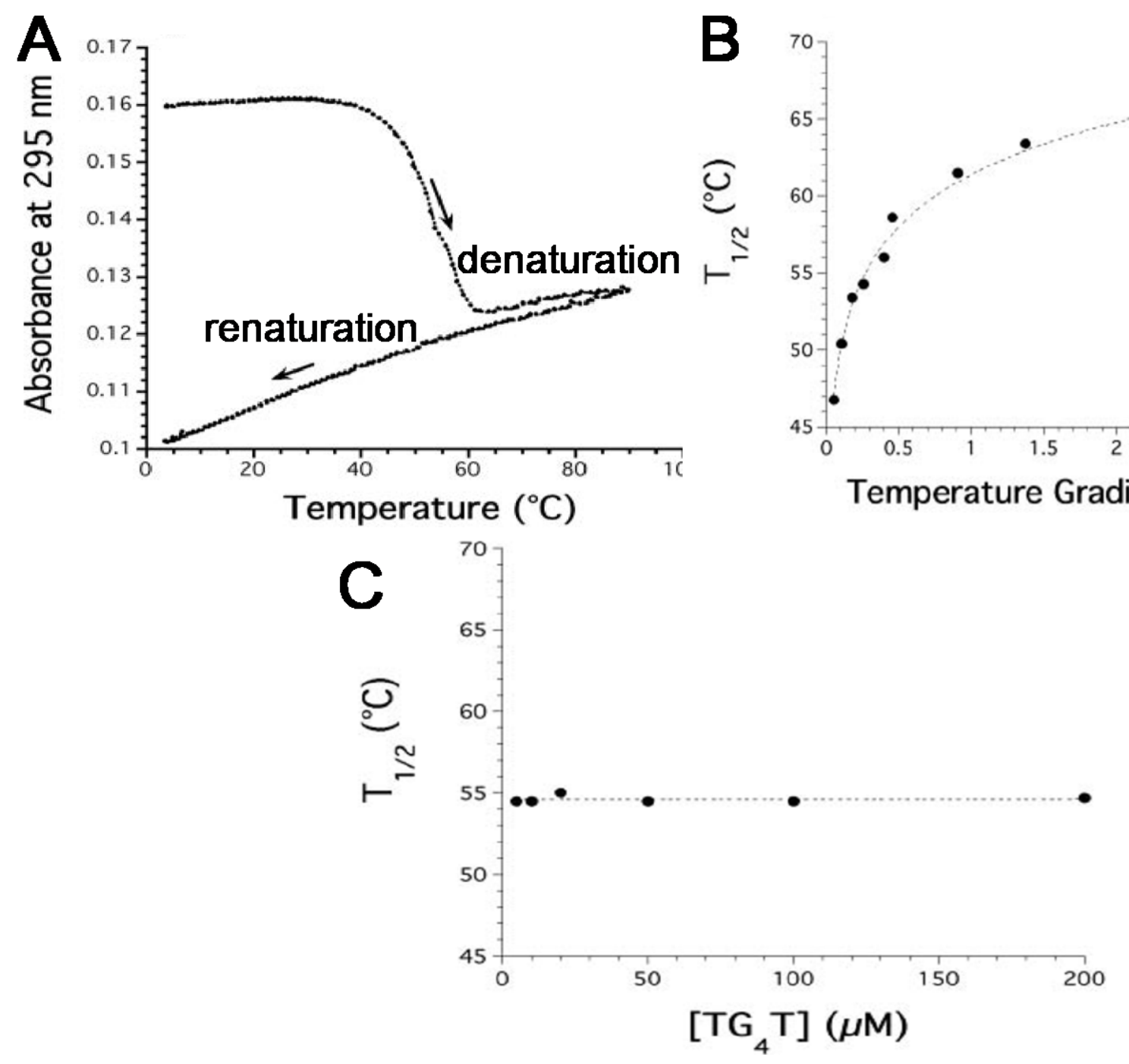




\section{Figure 9}
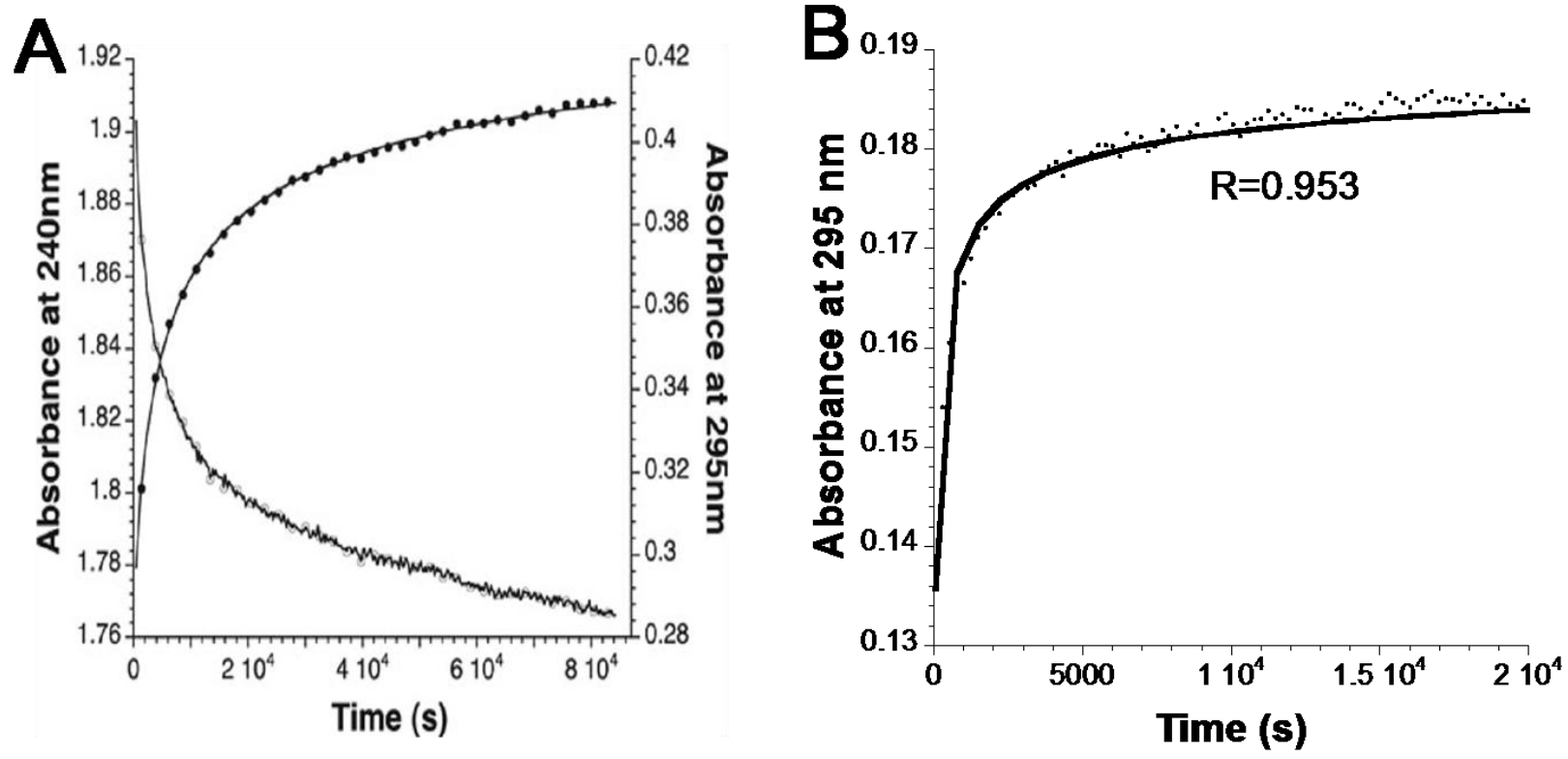


\section{Figure 10}

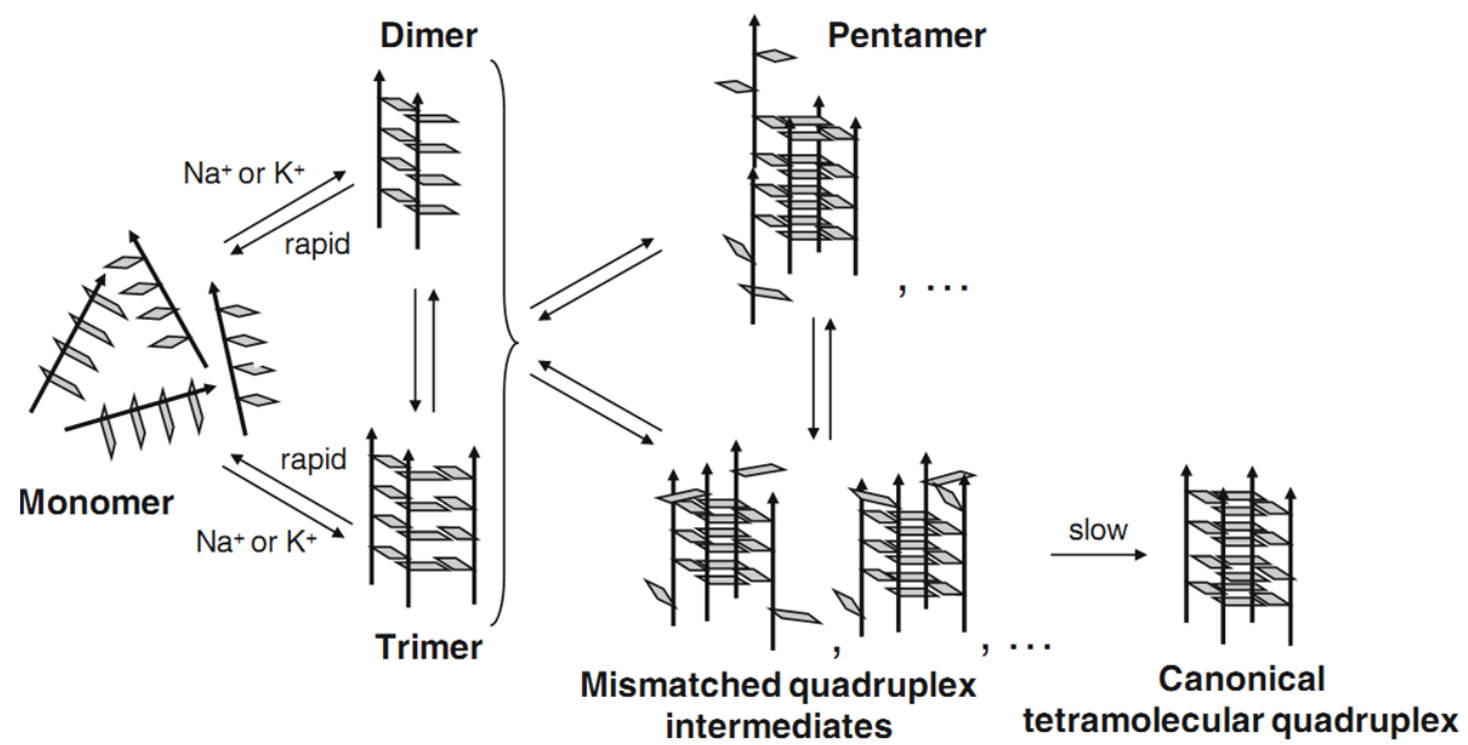


Figure 11

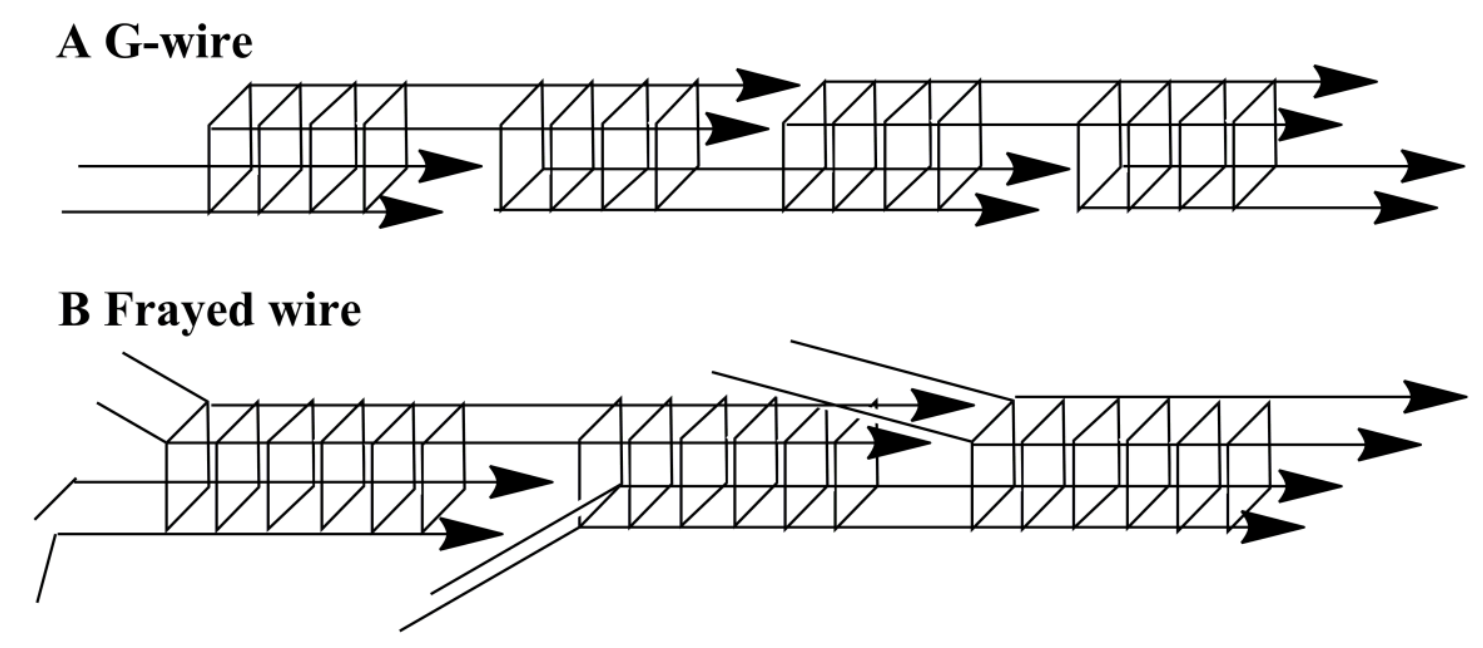

